\title{
A classification of structural inertia: Variations in structural response
}

\author{
Gavin M. Schwarz ${ }^{1}$ - Kuo-Pin Yang ${ }^{2}$. \\ Christine $\mathrm{Chou}^{2} \cdot$ Yu-Jen Chiu ${ }^{3}$
}

Published online: 28 June 2018

(C) Springer Science+Business Media, LLC, part of Springer Nature 2018

\begin{abstract}
Structurally inert firms suffer elevated failure risks in the face of environmental change because inertia makes it difficult to keep pace with the speed of such change. Traditionally, this ecology theory based outlook focuses on the risks of mortality, treating the make-up of an organization's architecture as uniform and thus relatively inconsequential for understanding this hazard. Renewing recent debates on inertia and on structure, in this paper we examine the specifics of the make-up of structural inertia in the context of failure hazards - the measurable survival risks associated with failure. Developing a classification of structural inertia, we test a sample of 755 firms listed on the Taiwanese Security Exchange across 52 industries to develop a convention on organizational structure, ratifying that structural inertia differs by type in incorporating failure hazards. Findings differentiate between and elaborate the validating environmental and resource conditions for these different categories, detailing the extent to which failure hazards are related to the specifics of
\end{abstract}

\author{
Gavin M. Schwarz \\ g.schwarz@unsw.edu.au \\ Kuo-Pin Yang \\ kpyang@mail.ndhu.edu.tw \\ Christine Chou \\ chou@mail.ndhu.edu.tw \\ Yu-Jen Chiu \\ d9732020@ems.ndhu.edu.tw
}

1 School of Management, UNSW Business School, University of New South Wales, UNSW, Sydney, NSW 2052, Australia

2 Department of International Business, National Dong Hwa University, No. 1, Sec. 2, Da Hsueh Rd., Shoufeng, Hualien 97401, Taiwan

3 Department of Marketing and Distribution Management, Oriental Institute of Technology, 58, Sihchuan Rd. Sec. 2, Ban-Qiao District, New Taipei City 22061, Taiwan 
each type. This variation is helpful in explaining better why, despite conditions leading to failure, inert organizations continue to thrive over time. Discussing this logic addresses the narrow representation of structural inertia and limitations to its theoretical development over several decades. It also shows that traditional organizational ecology measures can be legitimately underplayed in organizations dealing with increased failure hazards in favor of the characteristics of different structural inertia types.

Keywords Structural inertia - Organizational failure - Organizational structures · Organizational environments · Organizational ecology · Asia · Taiwan

Despite decades of scholarly focus and theorizing on managing change and success, failure and dealing with failing remains a captivating, persistent organizational feature (Bruton, Ahlstrom, \& Wan, 2003; Heine \& Rindfleisch, 2013; Ucbasaran, Shepherd, Lockett, \& Lyon, 2013). This constancy acknowledges the ongoing practical placement of failure in organizations, such as strategies for learning from failure (Shepherd, Patzelt, \& Wolfe, 2011), using failure to innovate (McKinley, Latham, \& Braun, 2014), or incorporating failure for improved performance (Birkinshaw \& Haas, 2016), as well as the ubiquity of corporate mortality (US Department of Labor, https://www.bls. gov/bdm/entrepreneurship/bdm_chart5.htm). Such endurance, however, also brings attention to the positioning of failure in debate on organizations and their features: Historically well-theorized as a seminal characteristic of all organizations, yet currently presented as either serving change themes or deeply contextualized to change processes (Lewis, 2015; Schwarz, 2012; Suddaby \& Foster, 2017). With this positioning and background, in this paper we seek to refresh discussion on structural inertia - one of the basic tenets of organizational ecology that centers on incorporating failure (Hannan \& Freeman, 1989; Mellahi \& Wilkinson, 2010). Specifically, we ask, do different types of structural inertia result in similar responses to failure hazards? With its foundation in an acceptance of the presence of failure, we study the make-up of structural inertia in the context of failure hazards, which are defined as a firm's measurable survival risks associated with failure (Dobrev \& Gotsopoulos, 2010). These hazards increase or decrease the extent of an organization's risk-taking and risk management in the face of environmental pressures and differences in resource utilization. In organizational ecology, failure hazards are a way of modeling stability, assuming that attempts at structural fit are associated with a risk of failure that needs to be managed (Hannan \& Freeman, 1984).

The value of asking this research question is related to the way that organizational ecology literature has tended increasingly to present a narrowed account of structural inertia and failure. Defined as the persistent organizational resistance to changing architectures (i.e., rather than shifting to new configurations as the environment changes, Hannan, Pólos, \& Carroll, 2004), it is widely agreed that structurally inert firms are more likely to be buffered by failure because inertia protects the firm from the liabilities and risks associated with change in an organizational population. Yet, while ecology research has advanced our understanding of the sources of inertia, there has been little contemporary insight into the make-up of structural inertia differences related to failure hazards, and the possibilities these differences offer. Recognizing this deficiency is consequential because it highlights that despite an ongoing tendency in organizational ecology to critically dissect established reasoning for homogeneity in 
organizational forms (e.g., Denrell, Liu, \& Mens, 2017; Lander \& Heugens, 2017; Yi, Knudsen, \& Becker, 2016), the tendency has been to embed structural inertia in this debate, assuming the placement of its parts (or used in support of debate on ecology trends). This gap in ongoing inertia development is understandable given that the abovementioned well-accepted ecology perspective assumes the value of structural stability and its failure connection. It predicts that organizations are a by-product of selection rather than adaptation, even in dynamic environments, because organizations that are reliable and accountable tend to reproduce structures and favor stability (or at least, difficulty changing, Hannan \& Freeman, 1977, 1984). With this reasoning, organizations that attempt change or reorganization are seen as risking weaker performance and mortality (Barnett \& Pontikes, 2008; Levinthal \& Posen, 2007; Yi et al., 2016) - that is, an increase in failure hazards.

Despite this validation, the problem with existing ecology literature on structural inertia is that it "has not advanced in parallel with [its] empirical work" (Hannan, Pólos, \& Carroll, 2007a: 231), particularly outside ecology themes and research; a paucity that leads to questions about its usefulness (Schwarz, 2012) and value (Donaldson, 1995). In response, focusing on a test of structural inertia differences, in this paper we contribute a more nuanced perspective on structural inertia, recognizing that it has been progressively sidelined in organizational research. Building on inroads made by Stieglitz, Knudsen, and Becker (2016) in showing that there can be variations in the levels of inertia that a firm experiences, we argue that while its features are established, structural inertia is far more dynamic than it is currently characterized. Through this variation we explain why, notwithstanding conditions leading to failure, inert organizations continue to thrive over time, based on the presence of different inertia types.

This examination acknowledges Hassard, Cox, and Rowlinson's (2013) note that in the constant search for new and exciting theories, organizational research may be overlooking historically developed paradigms that are still useful (but need updating). A brief cross-section of contemporary ecology research indicates that structural inertia theory is deeply embedded in dialog on organizations particularly because of its historical placement in organization theory (see Baum, Dobrev, \& Van Witteloostuijn, 2006; Gilbert, 2005, for such justification). At the same time, as Haveman and Kluttz (2015) pointed out, it is increasingly seen as having become narrower and less significant in the way we think about organizations. Central to this reaction is a view of structural inertia as overly complex and highly abstract, and "heavily rooted in biological Darwinian sociology, with little - if any-managerial relevance" (Dobrev, Van Witteloostuijn, \& Baum, 2006: 4). This view has led to a narrowing of structural inertia theory's appeal to contemporary organizational scholars. As a consequence, nuanced explanations of differences in structural inertia have a limited presence in ecology research, especially constraining depth to debate on how it might emerge differently. In response to this deficiency, while recognizing that there are already established differences in how inertia is represented (based on its established features, namely age, size, and strength, that Hannan and Freeman's [1984] original discussion raised), and the perpetual assumption in ecology theory that similar conditions give rise to a similar form of organization, this paper tests variations in structural inertia.

Thus, as a primary contribution on organizational structure, we broaden inertia theory by developing and testing a classification of structural inertia by type in an emerging economy. This approach enables a more extensive understanding of ways to 
study and apply this structure. Using a sample of 755 Taiwanese firms across different industries, we show structural inertia as a far more dynamic feature of organizations than it has been characterized, moderated by environmental jolts and slack resources of the organization. As core features of organizational ecology that govern the dynamics of how inertia is reinforced (Hannan \& Freeman, 1989), the way an environment suddenly diverges or changes (i.e., jolts), and how an organization uses or maintains its excess resources (i.e., slack) shows the potential for differences in the adoption of inertia types, which is especially relevant in the context of the story on Taiwanese organizational ecology. Taiwanese organizations have seen an economic evolution from a rapidly growing entity to a stabilized ecology by accommodating environmental jolts and resource slack. For instance, the experience in 2003 of Pan-International Electronics, a global provider of electronic manufacturing services, shows how leading Taiwanese firms dealt with the failure hazard caused by rapid market change from the outbreak of Severe Acute Respiratory Syndrome (SARS). Despite the negative impact on consumer demand, the firm increased investing in $R \& D$ and human resources, which eventually led to increases in profit and revenue. ${ }^{1}$ With this extension, this paper provides a framework to engage in a broader debate on structural inertia in particular, and architecture in general. These results promote a clear alternative to a conventional reading on how inertia thrives, especially in the context of structures in emerging Asian economies.

By using the classification, we also contribute to debate on structural choice, establishing a link in a growing area of debate (after Suddaby \& Foster, 2017) between structural inertia and time by showing that the relative advantages between each inertia type diminish in the short-term. This addition is especially significant to broadening how we approach structural inertia during change given inertia's historical connection to temporal patterning and failure. In addition, recognizing the progressive sidelining and narrowed appeal of structural inertia outside ecology, and with a core interest in developing ongoing debate in inertia, we demonstrate that structural inertia remains an emergent and changing organizational form relative to the choices and reasoning highlighted through the classification. Providing this more nuanced explanation reaffirms the ongoing value in inertia, and illustrates how organizations can engage with it differently, elaborating on the specifics of a broader call to arms for progress on structural inertia theory and practice.

This focus on differences by type recognizes that theorizing on organizational transformation and development has evolved to be far more extensive and engaged (Burke, 2017), while debate on structural inertia and failure remains embedded in advancing ecology themes, such as on architectural cascades (Hannan, Pólos, \& Carroll, 2003) or age dependence (Le Mens, Hannan, \& Pólos, 2015a). Specifically, we ratify a structural inertia classification through a test of (1) differences in survival risks associated with failure between specific different types, and (2) the role of environmental jolts and (3) resource slack relative to inertia type in response to failure. We test these hypotheses by considering failure hazards in the form of the structural consequences of financial distress of firms listed on the Taiwanese Security Exchange from 2000 to 2011. This choice represents an ideal setting to examine these issues

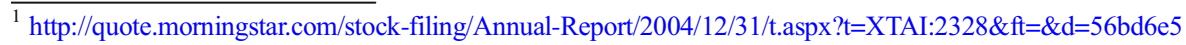
e99c3e9bf
} 
because of the regional failure pressures during this time period (via economic downturn), while Taiwan features an abundance of firms high in pyramidal control and control rights typical of inertia (Yang \& Schwarz, 2016). As a test of inertia and its relevancy, our classification of structural inertia by type provides the necessary framework to develop additional interest in and debate of structural inertia in organizational research, extending the geographic reach of empirical research on organizational structure to emerging economies. With this focus, we show that traditional organizational ecology measures can be legitimately underplayed in organizations dealing with increased failure hazards in favor of the characteristics of different structural inertia types.

\section{Literature review}

The problem with structural inertia in organizational research is that given its history and development, the construct is widely assumed to be "known"- that we know about inertia and what constitutes its parts, features, and measures. With this perspective, and given its presence in organizations, structural inertia has become seen as an establishment organizational theory. It is portrayed as an important but niche theory, and a construct that plays a moderating or secondary role in how we research organizations (e.g., Donaldson, 1995; Haveman \& Kluttz, 2015), rather than a core dimension to embellish further (i.e., than what we already know about or use).

Originating in organizational ecology, with its emphasis on how organizational populations adapt and evolve, and with a focus on the external influences that shape the diversity in organizational form, structural inertia considers the effects of environment on organizational structure. Facing pressures and constraints, organizations adopt structural inertia in order to fit their environment. The misfit of an organization leads to lower performance and therefore, reduced probability of survival (Hannan \& Freeman, 1977, 1984, 1989). At its foundation is the assumption that organizations are selected by the environment - that they need to fit closely with environmental requirements to survive - and those that do not fit disband or disappear. As Le Mens, Hannan, and Pólos (2015b) noted in an update, this perspective asserts that environments change because rivals introduce superior facilities, technologies, and strategies, and because market tastes evolve. At the same time, aging and large organizations cannot adapt well to these changes because of increasing inertial pressures, leading to performance declines. This approach assumes that in dynamic environments organizations seek a high degree of reliability (i.e., the ability to vary as little as possible in the quality and accuracy of its performance despite environmental demands), and high accountability (i.e., the demand for organizations to account rationally for decisions, rules, and actions). Accordingly, structural inertia is an evolutionary by-product of such selection because firms that are more reliable and accountable tend to reproduce structures. Reproducibility of structure then strengthens inertia, but it is an unintended consequence of selection. Paradoxically, inert firms then suffer the risk of elevated mortality hazards in the face of environmental change since inertia makes it difficult to keep pace with the speed of environmental change.

With a focus on this selection process, and its view that foundings and failures drive organizational populations and change, ecologists assume that organizations are subject 
to strong inertia forces because, once founded their structures do not change much over time. For Hannan and Freeman (1977), structural inertia was used to justify this assertion and the claim that organizations with features that match environmental requirements have a competitive advantage and therefore are selected for survival. Simply put, "as the attributes of the environment encompassing populations of organizations shift over time, the dominant attributes of the organizations in the population also shift, but through a process of selection and culling rather than a process of individual organizational adaptation" (McKinley \& Mone, 2003: 358). Structural inertia is a by-product of this process suggesting that any attempt at reorganization is a risky proposition because it increases the possibility of failure (i.e., mortality).

Given the provocative nature of this resistance to change thesis and its focus on the place and value of failure, inertia theory has attained almost paradigmatic status in organizational research. Debate on structural inertia is embedded in organizational theory, which has then limited its accessibility to non-ecology researchers. As a result, a scan of macro-organizational failure literature indicates that structural inertia is not a substantive driver of this discussion (see reviews by McKinley et al., 2014; Trahms, Ndofor, \& Sirmon, 2013). While deeply-rooted, in keeping with the relative value of macro-organizational scholarship on the field (Certo, Sirmon, \& Brymer, 2010) and criticism of its complexity and usefulness (Donaldson, 1995), it has become an acceptable, integrated feature of contemporary organization discussion. Organizational researchers explore broad inertia themes such as its sources (Dunbar \& Ahlstrom, 1995; Gilbert, 2005), its conditions (Dew, Goldfarb, \& Sarasvathy, 2006), or its effects (Ruef, 2006). But they tend to do so incorporating rather than developing Hannan and Freeman's (1984) original representation of it, or challenges to its portrayal of failure.

This shortcoming is especially valid given that although applied discussion on organizational design and structure has continued to advance (Christensen \& Raynor, 2013), and although there is progress in inertia commentary (e.g., on age, environment, adaptation, and routine, Håkonsson, Klaas, \& Carroll, 2013; Yi et al., 2016) debate still tends to theorize structural inertia based on the tenet that organizations are unable (or unwilling) to initiate changes to its core features (made up of the organization's mission or goals, its forms of authority, basic technology used to transform inputs into outputs, and general marketing strategy). This tendency is particularly noticeable when compared to the advances made in theories embedded in ecology themes, such as the growth in institutional theory, which originally relied on Hannan and Freeman's (1984) explanation of organizational form and on inertia strength. Further highlighting the progression of this debate limitation, there are several developments in decisionmaking and in change research that incorporate new interpretations of inertia or its placement, such as Barnett and Pontikes' (2008) success bias argument on the risks of change or Hannan et al.'s (2007a) proposal to consider the "microfoundations" of the theory, specifically related to the character of structural arrangements and processes.

The consequence of this problem with inertia is that it results in a failure to realize advances made (rather than its underpinning idea), restricting its broader use and impact, a theme that Le Mens et al. (2015a) underscored. Instead, when there has been a dedicated focus on structural inertia, attention is given to testing its original theorems and propositions, establishing its features, and explaining the curvilinear effect of 
inertia in particular industries (see Baum et al., 2006). Recognizing the risks of this problem to how we think about inertia in organizations, and as part of a contemporary extension, we present a classification of structural inertia to examine the extent to which different structural inertia responses exist, based on how inertia is reasoned.

\section{A classification of structural inertia responses}

It is broadly acknowledged but under-explored that inert organizations in populations have the potential to vary structurally (Haveman \& Kluttz, 2015) and that organizations adopting structural inertia are often pressured to do so (Le Mens et al., 2015b). Using these assertions, and recognizing Stieglitz et al.'s (2016) work showing the flexibility available to inertia in dynamic environments, we propose that there are different types of inertia possible. We make this proposal recognizing the aforementioned problem with inertia and that structural inertia is (still) a constant feature of contemporary organizations.

At the base of the classification is an acknowledgement that there are examples of variations in structural inertia, such as Gilbert's (2005) categorization of different inertia sources to explain possible alternative explanations for structural inertia decisions, or Yi et al.'s (2016) work on inertia in routines. Similarly, Schwarz (2012) noted that there are different ways of approaching inertia during change. But such accounts are limited because they typically theorize on the "path" organizations adopt structurally once they make a decision (leading to failure and decline). In this context, it is interesting to note that Hannan (and some colleagues) spent at least a decade reorienting the original inertia thesis to be conceptually broader (see Hannan et al., 2003, 2004; Peli, Pólos, \& Hannan, 2000; Ruef, 2006; Simons \& Ingram, 2004), with allied assertions on the limitations of not adequately developing its underlying phenomenon.

\section{Structural inertia types and their adoption}

The essence of the classification is that it proposes different paths in how firms adopt (or maintain) structural inertia preferences related to a combination of discretionary and contextual factors. In keeping with ecology approaches, the focus is on individual firms within a broader population, as well as the selection process inherent in structural inertia - the adjustment in the extent to which organizations maintain stable structures as their environments change. Using this focus, we draw on Wholey and Brittain's (1989) contention that there are multiple possible patterns in how organizations form and operate, guided by environmental variation, a notion supported by Schwarz (2012) specific to differences within structural inertia. Doing so, we incorporate Hannan and Freeman's (1984) assertion that when inertial pressures are sufficiently strong, mobility to another form of organizing is unlikely. This selection establishes that there are variations in the strength of inertia for different organizations, referring to age, size, and resource pressures as an organization's environment changes (and impacting survival risks associated with failure; see Hannan \& Freeman, 1984: 161 and Hannan \& Freeman, 1989: 80 for measures of variations in strength). Recognizing this strength continuum is key to establishing the possibility for a classification of inertia differences by type. Such variation arises from external, environment pressures and internal, resource capacity 
pressures, and enables structural inertia to vary from one class of organization to another. Using this difference and based on the selection constraints it promotes allows us to formulate four types of inertia (restricted, coincidental, habitual, and purposive).

Restricted inertia is a bounded or circumscribed structural inertia type response. The organization does not have adequate resources available to commit to a new course of action to facilitate structural change, leading to inertia selection via a slower pace of change over time. Without flexibility, it is difficult to change structure quickly while firms cannot reverse ineffective strategic choices (Shimizu \& Hitt, 2004; Yi et al., 2016). Even though a need to change may be favored, with inadequate resources to support this recognition, substantive structural changes are unable to be made, reinforcing inertia, such as how IBM's inertia progressively evolved in the face of start-up competitors (Christensen, 2013). This limitation response makes a firm unable to remobilize and change structurally. Consequently, and relevant to a test of the classification, we predict that restricted structural inertia firms will be the most tenuous because they have the highest failure hazard of all inertia types (i.e., the highest risks associated with failure hazards).

Coincidental inertia is a sudden or reactive structural inertia response. Uncertainty prompted by the environment leads to an uncoordinated response to the organizational population, thereby reinforcing the value of maintaining structural inertia rather than changing. In this context, structural inertia is viewed as part of an institutional identity. For instance, such as how Firestone Tire and Rubber remained structurally inert in the face of a need to respond to a changing marketplace, leading to significant changes in the firm's market share (Sull, 2005). The basis of this type is that the organization does not have adequate access to resources already committed or does not have certainty in its resourcing. Without this resource mobility the organization responds to change by unexpectedly slowing down any possible reorganization, thereby unintentionally strengthening the structural status quo. Since this type of structural inertia response is inadvertent, it achieves a coincidental fit with population-led environmental pressures, and subsequently tends to have a high failure hazard (i.e., an increased risk associated with failure hazards).

Habitual inertia is an accommodating structural inertia response-its accommodation occurs when dealing with change. It recognizes the role that routines play in enabling stability through repeatable and reliable organizational activities (Yi et al., 2016). This type is based on an assumption that while structural changes are feasible and possible, routine hinders organizational adaptation and facilitates the retention of structure, providing advantages for survival and efficiency, such as the inertia associated with government department routine and its associated bureaucracy. With adequate access to resources the organization actively retains inertia. Rather than consider structural change alternatives, the routine embedded in structural inertia is viewed as a way to maintain the advantages of stability. This response is justified on the basis that reliability (or certainty) is central to structural inertia and that inertia is relative (i.e., that firms change less than markets do). This habit allows actors to rely on repetitive responses and practices (see Simon, 1997), establishing the value of highly reproducible structure. With the firm reinforcing existing resourcing and routine patterns, as part of a test on this classification we maintain that habitual inertia types will carry a moderate failure hazard (i.e., a lower failure hazard than restricted types, but a higher risk than coincidental inertia types). 
Purposive inertia is the highest strength validation of structural inertia at the opposite end of the scale to restricted inertia. Because of the pressure of the status quo to select inertia, the firm chooses to match its institutional identity or reputation to the organizational population. Environmental pressure is recognized, and the focus is on conformity and limiting structural variability as a means of allocating available resources and available organizational actions. As Le Mens et al. (2015b) noted, a preference for the status quo becomes self-reinforcing over time, with the longer that a structure is in place the more likely the organization opposes structural change. For example, Gilbert (2005) showed how newspaper organizations responded to digital media by validating inertia, absorbing this change in operations into existent structures. The basis of this type is that a degree of certainty in resources gives the organization the capacity for consistent performance. In keeping with structural inertia theory findings on the advantages of the rigidity of organizational structures and adopting strong inertia (Amburgey, Kelly, \& Barnett, 1993; Hannan et al., 2007a), we predict that purposive structural inertia types will have the lowest failure hazard of all inertia types (i.e., lowest risk associated with failure hazards).

Noting Hannan and Freeman's (1977) emphasis of the possibility of variations in the strength of inertia, and given our abovementioned expectations for failure hazard risks, we hypothesize a test of this classification using purposive inertia - the highest strength option-as a benchmark.

Hypothesis 1 Organizations adopting purposive structural inertia will have the lowest survival risk associated with failure, compared to other inertia types.

\section{Environmental jolts and structural inertia responses}

Essential to the extent to which different structural inertia responses exist, based on how inertia is reasoned, is a consideration of the environment and if some organizations adopt a particular type when environment shifts (and whether there is an associated failure hazard). Tests of inertia theory maintain that a dynamic environment presents clear risks to organizations if they change strategies and structures as quickly as or in response to their environments (e.g., Dobrev, Kim, \& Carroll, 2003; Le Mens et al., 2015a, 2015b). Environmental change is seen as constraining an organization's ability to reorganize (e.g., de Figueiredo, Rawley, \& Rider, 2015; Zaheer, 1995). At its simplest, organizations "are highly vulnerable to environmental shocks" (Hannan \& Freeman, 1984: 161) subjecting them to strong legitimacy constraints. This pressure limits an ability to change structure, based on not being able to adapt quickly enough to changing conditions (Ruef, 2004), or acts as a barrier to reversing a course of action when environmental conditions change (Davis, Eisenhardt, \& Bingham, 2009). Fundamentally, environmental selection favors structural stability and therefore, structurally inert firms. Consequently, ecology approaches assume that organizations facing the threat of dynamic environments are best to reinforce inertia rather than promote systematic structural change (Denrell et al., 2017; Yi et al., 2016). We consider this relationship for different inertia types in the context of failure hazards.

Given this basis, and in contextualizing the adoption of inertia, most ecology research has tended to present environment as a constant feature of the selection 
process, fundamental to low rates of initiating structural change. Environment change is therefore a moderator in testing inertia and its selection. The typical focus in considering inertia is on detailing the process of adjustment or constraint rather than a specific inertia effect (see Barnett \& Pontikes, 2008; Singh \& Lumsden, 1990). In response, and recognizing this impact of environment in determining inertia strength, we test inertia types by focusing on short-term environmental jolts. After all, if environmental selection is key to inertia strength differences, then what is the impact by type when the environment is either not stable or predictable? This test acknowledges the ongoing questioning in inertia-related research (Lampel \& Jha, 2017; Stieglitz et al., 2016) on the nature of the adoption of structural inertia in dynamic environments.

As Meyer (1982: 515) defines it, an environmental jolt is "a sudden and unprecedented event...whose occurrences are difficult to foresee" and whose impacts on organizations are disruptive and potentially unfavorable. For instance, sudden economic downturns and unexpected government policy changes impact all organizations (Bradley, Aldrich, Shepherd, \& Wiklund, 2011). A jolt can prompt perceptions that contrast with expectations and which precipitate action intended to avoid dramatic outcomes. It may provide stimuli or trigger responses that reveal how organizations adapt to change, making them an effective means of assessing firms and their reactions. Recognizing the placement of environment shocks to an increase in failure risks (Hannan \& Freeman, 1989), and Bradley et al.'s (2011) use of jolts in exploring mortality rates, we focus on the impact of short-term jolts because it allows a test of inertia types in different conditions. It also encompasses the core features of inertia theory, (1) timing - small change in environments are commonly thought to present firms with clear, measurable risks and challenges over time (Wan \& Yiu, 2009), (2) speed - they are "transitory blips" (Meyer, 1982), rather than permanent features, thereby inducing a variety of different possible structural responses, and (3) responsiveness - they affect both organizations and individuals, offering an effective means of assessing the micro-level aspect of inertia types (Berger \& Le Mens, 2009).

It is this connection between a jolt's impact and its related pressure on an organization's strategy and structure that explicitly links differences in environment to structural inertia types. Consequently, and as part of our focus, environmental jolts raise questions about what is the effect of specific environmental change on the likelihood of similarities or differences in structural inertia responses to failure hazards. Our classification of structural inertia by types expects a structural reaction to environmental pressures associated with failure, rather than the environment itself. Environment matters, but selection still favors inert organizations (Hannan \& Freeman, 1984; Stieglitz et al., 2016). In this sense, and as a test of this principle by type, we anticipate that when an environment "jolts" (i.e., suddenly diverges or changes) it produces a systematic impact for all organizations regardless of inertia type, and even if some types display more relative advantage than others. Sudden disturbances in environment will disrupt or minimize potential differences in the adoption of inertia types. Thus, in a clear advance to inertia theory's portrayal of environment, we hypothesize that short-term jolts neutralize the relationship between inertia type and risk to the organization of failure hazards.

Hypothesis 2 Environmental jolts moderate the adoption of different structural inertia types such that associated failure hazards are homogenous for all types. 


\section{Excess resources and structural inertia responses}

As part of a discussion on the risk associated with organizational ecology, and given the connection that organizations have with their environment, resources and how resources are utilized are intrinsic to how organizations adapt and respond to the actions of populations. Specifically, resources are seen to play a role in generating competitive advantage and presenting growth opportunities (Barney, 1991). In this way, inertia presents an interesting dichotomy. While valuing the usefulness of resources, as Freeman, Carroll, and Hannan (1983) argued, the failure risks associated with inertia are relative to mobilizing resources. Specifically, because organizations depend on other organizations for the resources they require, "once such resources have been invested in building an organizational structure, they are difficult to recover" (Hannan \& Freeman, 1984: 152) strengthening the status quo. Organizations tend to maintain excess capacity in the resources they hold to remain viable when conditions change. This dependence on the stock of excess resources reinforces inertia as a by-product of selection, and raises the failure risks of being inert through the inefficiencies of lost (possible) resources or of the need for required resources. Thus, resources are essential to the reliability and accountability competencies that characterize organizational ecology and lead to highly reproducible structures. Yet despite this outcome (e.g., Bradley et al., 2011), and in keeping with the tenor of the inertia problem we detail earlier, inertia research tends to use excess resources as a point of departure and discussion, rather than question the extent to which slack differences promote structural stability. It is in this context that we explore different types of structural inertia and responses to failure hazards in terms of excess resources.

How an organization uses and maintains its excess resources enhances its likelihood of survival. This patterning in the way that organizations structure and compete related to the efficiencies from maintaining excess resource capacity has become known as "slack" (Sharfman, Wolf, Chase, \& Tansik, 1988). Resource slack refers to "a cushion of resources that allows an organization to adapt to internal or external pressures as well as to initiate changes in strategy in regard to the external environment" (Bourgeois, 1981: 30). Slack can play either a beneficial or detrimental role relative to a firm's structural response, fueling innovation and promoting risk-taking while also reducing experimentation and hindering growth (see Dolmans, van Burg, Reymen, \& Romme, 2014). As part of a discussion of the social environment of individual organizations and populations of organizations, inertia theory proposes that change in the environment of one organizational population usually means changes in the composition or activities of other organizational populations. Key to this selection is that organizations adjust structure to ensure a continued flow of slack resources, such as accumulating capital, employee commitment, or skills. In promoting their thesis, Hannan and Freeman (1984, 1989) argued that the way individual organizations select in populations depends in part on the extent of the excess resources it holds, giving it a capacity to respond to its environment. Reproducible structures in the form of inertia are a favored means of managing this response.

From this perspective, slack is relevant to a test of different inertia types given that excess resources directly affect an organization's structure, as Cheng and Kesner (1997) indicated empirically. When slack is high (and the firm can use the excess resources as a buffer), organizations have more structural freedom and are able to select structures 
regardless of environmental pressures. But when slack is low (and the firm cannot afford to be unresponsive to the environment), its structure is more likely to be contingent on conditions and ecological requirements. This idea indicates that how organizations respond to slack resources will determine the strength of inertia. It is this connection between a firm's resource slack and the impact on its internal strategy that informs differences in inertia type responses. As we indicated earlier, restricted and coincidental inertia types are characterized by limits to their resources and less certainty (low slack), while habitual and purposive types have resource access and more certainty (high slack). Within this delineation, purposive inertia relies most on excess resources and is therefore an appropriate measurement benchmark to show how an organization deals structurally with its excess resource capacity.

To test the accuracy of these resource-based differences, we focus on how slack resources are distributed by type, and specifically related to the absorbed slack effects. Absorbed resources refer to excesses that are embedded in the organization through allocation to specific tasks or routines, such as working capital or specific human resources. Given that they are tied up with current operations, they are not easy to redeploy, making them more likely to support inertia. Moreover, having been shown to have a lagged performance effect (Tan \& Peng, 2003) and given the long-term focus in our classification, we are particularly interested in the moderating role it plays. By contrast, unabsorbed (or available) resources refer to excessive and current resources that are not assigned and uncommitted to specific tasks and are highly flexible or easily redeployed, such as cash and marketable securities. Financial resources have been typecast as unabsorbed, helping to reduce or manage failure rates (e.g., George, 2005; Voss, Sirdeshmukh, \& Voss, 2008). With this distinction in mind, we predict clear differences in responses to failure hazards relative to resources through a test of absorbed resource slack. This consideration acknowledges the well-documented role of slack in buffering the impacts that endanger firm survival (e.g., Cheng \& Kesner, 1997; George, 2005; Thornhill \& Amit, 2003). With this knowledge, and recognizing that organizations seek out and use reliable resources to reproduce and retain structure over time, we focus a test of absorbed slack and purposive inertia to highlight resource promoted differences in inertia types. Acknowledging the stringencies of absorbed slack, and the long-term effect of slack resources, we predict that those firms adopting purposive inertia, with its high slack relative to its dependence on environmental pressure, will make this inertia type best able to respond to failure hazards, relative to other types.

Hypothesis 3 Absorbed resource slack strengthens the advantage of purposive inertia relative to other inertia types, in response to failure hazards.

\section{Methods}

\section{Research design and sample}

To test the classification of inertia responses, we considered failure hazards in the form of the stock trade regulation due to financial distress of firms listed on the Taiwanese Stock Exchange (TWSE). After experiencing rapid, high growth in the 1980s and '90s, 
the Taiwanese economy moved to a stabilized growth pattern (Liu, Chen, \& Wang, 2017). This transition (with its accompanying failure hazards) provides an ideal setting to examine inertia differences and for observing how firms respond to environment changes through their organizational structures. Further, in this market there is a prevalence of business groups and firms that are high in pyramidal control, authority patterns, and decision-making characteristic of inertia and stable family control (Hamilton \& Biggart, 1988; Yang \& Schwarz, 2016).

The study uses a sample drawn from a widely-used economic database maintained by Taiwan Economic Journal (TEJ) which provides the most comprehensive information of listed companies in Taiwan, for the period between 2000 and 2011. This timing was selected to encompass significant environmental jolts and resource challenges. During this period, but particularly from 2003 through 2005, Taiwan and Asian countries suffered an ongoing economic downturn caused by the outbreak of Severe Acute Respiratory Syndrome (SARS). The 2003 SARS epidemic was a viral form of pneumonia that spread rapidly from China and Hong Kong throughout the region, affecting 32 countries and infecting as many as 8000 people and killing 750 (Chou, Kuo, \& Peng, 2004; Peiris et al., 2003). The effect on national economies was intense, with a reduction in travel and investment estimated to be in the range of US\$30-140 billion up until 2005 (Skowronski et al., 2005). For example, when compared with the same period a year earlier, Taiwan's GDP created by its air transport, securities and futures, and real estate sectors fell by $22.7,26.1$, and $7.7 \%$, respectively (Chou et al., 2004). Due to globalization, SARS led to a substantial decline in consumer demand and resource utilization, reduced the confidence in the future of the affected economies, and increased the cost of disease prevention such as the travel and retail sales service sectors worldwide (Lee \& McKibbin, 2004). SARS was regarded as a crisis for Asia in general and for Taiwan in particular (Bennett, Chiang, \& Malani, 2015). Following Wan and Yiu's (2009) categorization of the Southeast Asian economic crisis of the 1990s, SARS represents a major, short-term environmental jolt that suddenly and dramatically impacted on resource slack.

\section{Sample and data}

The study sample consisted of 1979 firms across 52 industries listed on the TWSE. It excludes foreign companies, financial holdings, and other listings with incomplete data. Recognizing the selection-based definition of structural inertia as the persistent organizational resistance to wholesale architectural changes - and that inertia theory concentrates on the selection process - these data were initially used to distinguish structurally inert firms (and low rate of reorganization) from structurally active (and adaptive, responsive change) ones by categorizing the extent to which there is substantial system, procedural, or process change over time. These structural change features were observed as the extent of product diversification (an entropy index to incorporate resource slack) and internationalization (the ratio of foreign sales to total sales used to incorporate environmental jolt) to distinguish structurally inert from active firms. This delineation ensures that our primary focus is on inertia, recognizing Haveman and Kluttz's (2015) assertion that a test of inertia tends to center on its causes and consequences rather than the inertia itself. 
To categorize inertia by type, we relied on established measures that record the reproducibility of the structure of individual organizations in response to populations of organizations (after Hannan \& Freeman, 1989, and using Barnett \& Carroll, 1995; Kelly \& Amburgey, 1991). These measures consider the ratio of the changing status in products and markets of a firm relative to the average changing status of its corresponding market sector. Doing so, a firm that simultaneously changed its levels of product diversification and internationalization at speeds lower than the average rates of changes in the population over the observation period was classified as structurally inert. From the total sample, this criterion filtered 755 (38.2\%) firms as inert, of which 517 were coded as "surviving" and 238 (31.5\%) as "delisted" (or failed). The final sample of all inert firms contains 6084 firm-year observations across 52 industries. The classification of industries was mostly based on the 2-digit SIC codes, except for the electronics and information industry, whose detail required the use of the 3-digit codes.

To classify structurally inert firm differences, we measured two dimensions. For the first dimension, to differentiate a firm's resource slack we calculated a composite factor score comprising the ratio of R\&D expenses to sales (Daniel, Lohrke, Fornaciari, \& Turner, 2004), the ratio of the number of employees to sales (Greenley \& Oktemgil, 1998; Mishina, Pollock, \& Porac, 2004), the ratio of equity to debt (Hambrick \& D'Aveni, 1988; Wan \& Yiu, 2009), and the ratio of current assets to current liabilities (Bromiley, 1991; Greenley \& Oktemgil, 1998). We used the mean score to dichotomize all sampled firms into low and high subgroups. For the second dimension, environmental pressure for inertia was measured based on new entry rate and industrial life stages. Mature and declining industries exhibit relatively low entry rates compared to those in early and growing cycles (Agarwal \& Sarkar, 2002). As an industry ages, ecological pressure demands an increasing level of structural inertia from organizations for a better chance of survival. In line with this argument, we regard those industries older than the third quartile $(75 \%)$ of the distribution of all industry ages, and with no new entrants during observation period, as mature and declining industries that demand a higher level of inertia than those younger. In total, 32 industries were classified as mature and declining. Based on these dimensions, $325(43.1 \%)$ firms were classified as restricted type inertia, $200(26.5 \%)$ as coincidental type, $104(13.8 \%)$ as purposive type, and 126 $(16.7 \%)$ as habitual type.

\section{Measures}

Dependent variable With its focus on the survival risks associated with failure, Failure hazard was measured by the regulation of stock trading relative to those listed on the TWSE, excluding voluntarily delisting ones (e.g., merger and acquisition). To protect investors, the TWSE strictly regulates the trade of stocks of listed firms suffering financial distress and classifies them into three categories: full-cash delivery, trading suspension, and mandatory delisting. This measure recognizes that an organization risks failure when its ability to compete deteriorates and its performance falls below a critical threshold that makes it unviable (Mellahi \& Wilkinson, 2010). The occurrence of failure was measured by a dummy variable coded as one if the firm fell into any of the three categories of regulated stock trading, and as zero otherwise (Agarwal \& Sarkar, 2002). 
Independent variables Inertia types were represented by several dummy variables, values of 0 and 1 , to achieve contrast purpose in different statistical models. An Environmental jolt was also measured by a dummy variable, coded as 1 during the years of 2003-2005 to reflect the impact of economic downturn caused by the SARS, otherwise coded as 0 . We used the ratio of R\&D expenses to sales (Daniel et al., 2004) and the ratio of the number of employees to sales (Greenley \& Oktemgil, 1998; Mishina et al., 2004) to form the proxy of Absorbed slack resource (with low degree of mobility), and the ratio of equity to debt (Wan \& Yiu, 2009) and the ratio of current assets to current liabilities (Greenley \& Oktemgil, 1998) to form the proxy of Unabsorbed slack resource (with high degree of mobility). An exploratory factor analysis on the four measures was conducted and the results confirm the appropriateness of the composition of the absorbed and unabsorbed slack resource. The principal component method was subsequently used to form a composite factor score as the surrogate of a firm's absorbed and unabsorbed slack resource respectively.

Control variables Given their centrality in theorizing on structural inertia, the effects of several traditional ecological features were included as controls. These controls consisted of industry- and firm-level variables. For the former, for each observation year Industry age was measured by the proxy of the oldest firm age in an industry (McKendrick \& Wade, 2010). Industry density was measured by the total number of firms in the same industry each year (Hannan \& Freeman, 1989). Concentration rate was measured by the market share represented by the largest four companies in an industry (i.e., the CR-4; Bain, 1956). Because the Electronics industry represents the largest sector in the sample, it was controlled for with a dummy variable. For a pure test of environmental jolt, the study also controlled for the influence of fluctuations in macro economy by including GDP growth rate in the model.

For firm level control variables, we recognize the tendency in ecology research to study structural inertia by considering age and size dependencies, especially given Hannan et al.'s (2007a) findings on the link to an age dependence in organizational mortality. The liability of aging hypothesis predicts an increasing rate of failure for older organizations as a result of the aging process (Baum et al., 2006). Firm age was measured by the difference between observation year and a firm's inception year. Firm size was measured by the logarithm of total asset (Haveman, 1992). Prior performance was considered highly associated with firm resource and survival (Wiersema \& Bantel, 1992) and, thus, was controlled with the return on asset (ROA) of prior year (Daniel et al., 2004). Given the link between failure and corporate governance, the effect of Board size in terms of the number of board seats (Goodstein, Gautam, \& Boeker, 1994; Pearce \& Zahra, 1992) was included as a control in the analysis. Finally, to test the moderating effect of absorbed slack, this study controlled for another type of slack resource, namely, Unabsorbed slack resource in the models.

\section{Modeling Data}

Following trends in previous research on organizational failure (McKendrick \& Wade, 2010; Shumway, 2001), the Cox proportional hazard model has been shown to be a better estimation method of failure than other techniques. The model (Cox, 1972) 
represents the change ratio of a dependent variable associated with a unit change in the independent variable. In testing the hypotheses, the dependent variable (i.e., the failure hazard) is the probability that an individual firm will delist at time $t$ given that the firm is at risk at time $t$. Thus, the hazard rate in the Cox proportional hazard model function, denoted by $\mathrm{h}(t)$, gives the probability of delisting of the firm beyond a specific time $t$. This function can be written as:

$$
\mathrm{h}(t \mid \mathrm{X}, \beta)=\lambda_{0}(t) \exp \left(\mathrm{X}^{\prime} \beta\right)
$$

The parameters $\lambda_{0}(t)$ is the baseline hazard rate function providing the time $t$ for the standard set of conditions by the vector $X$, which is assumed $0 ; X^{\prime}$ represents the independent variables $\left(\mathrm{X}_{1}, \ldots, \mathrm{X}_{p}\right)$ that change with time; $\beta$ is a vector of regression coefficients (Cox, 1972), expressed as exponentiated hazard ratios (i.e., $\operatorname{Exp}(\beta s))$ in this study.

\section{Results}

Table 1 presents the sample distributions by inertia type and their corresponding failure/ survival statistics in two time periods (the SARS and non-SARS periods). The impact of this environmental jolt is observable, where the yearly failure rates for the first three inertia types (except for the purposive type) were all higher in the SARS period than in the non-SARS period. Initial comparisons show that the highest failure rate occurs to the restricted inertia firms $(41.2 \%)$, followed by habitual inertia $(30.2 \%)$, coincidental inertia $(27.0 \%)$, and then purposive inertia (11.5\%). Although the ranks applied to both

Table 1 Sample distribution, types of inertia, and failure rates

\begin{tabular}{|c|c|c|c|c|}
\hline & $\begin{array}{l}\text { Restricted } \\
\text { inertia }\end{array}$ & $\begin{array}{l}\text { Coincidental } \\
\text { inertia }\end{array}$ & $\begin{array}{l}\text { Habitual } \\
\text { inertia }\end{array}$ & $\begin{array}{l}\text { Purposive } \\
\text { inertia }\end{array}$ \\
\hline Number of structurally inert firms & 325 & 200 & 126 & 104 \\
\hline Number of structurally active firms & 191 & 146 & 88 & 92 \\
\hline Number of delisted firms & 134 & 54 & 38 & 12 \\
\hline Failure rates $(\%)$ & $41.23 \%$ & $27.00 \%$ & $30.16 \%$ & $11.54 \%$ \\
\hline Yearly failure rates $(\%)$ & $3.44 \%$ & $2.25 \%$ & $2.51 \%$ & $.96 \%$ \\
\hline \multicolumn{5}{|l|}{ During non-SARS period ( 9 years) } \\
\hline Number of delisted firms & 74 & 31 & 20 & 2 \\
\hline Failure rates $(\%)$ & $22.77 \%$ & $15.50 \%$ & $15.87 \%$ & $1.92 \%$ \\
\hline Yearly failure rates $(\%)$ & $2.53 \%$ & $1.72 \%$ & $1.76 \%$ & $.21 \%$ \\
\hline \multicolumn{5}{|l|}{ During the SARS period (3 years) } \\
\hline Number of delisted firms & 60 & 23 & 18 & 10 \\
\hline $\begin{array}{l}\text { Failure rates over } 12 \text {-year period } \\
(\%)\end{array}$ & $18.46 \%$ & $11.50 \%$ & $14.29 \%$ & $9.62 \%$ \\
\hline Yearly failure rates $(\%)$ & $6.15 \%$ & $3.83 \%$ & $4.76 \%$ & $3.21 \%$ \\
\hline
\end{tabular}


periods with or without SARS, the differences in failure rates among the four inertia types tend to converge during the SARS jolt period.

Table 2 presents the means, standard deviations, and correlation coefficients between the variables. Overall, correlation coefficients are moderately low except that four correlation coefficients were found slightly high between the electronics industry and industry density, between the electronics industry and firm age, between industry density and industry concentration, and between firm age and firm size. The high correlations are reasonable because approximately $48 \%$ of all sample firms belong to the (country-specific) electronics industry, leading to a high degree of industry density. In addition, the Taiwanese electronics industry is younger compared to its other manufacturing industries. A low industry density naturally leads to a high degree of market concentration and aged firms are generally scaled.

Table 3 reports results on $\mathrm{H} 1$ and $\mathrm{H} 2$. It demonstrates these results according to two different time periods of observation, each containing two hierarchical models with control model in the first place (Models 1 and 3), followed by a main-effect model (Models 2 and 4). During the complete observation period (2000-2011), the regression coefficients for restricted inertia type $(\beta=1.125, p<.01)$, coincidental inertia type $(\beta=.681, p<.05)$, and habitual inertia type $(\beta=.618, p<.05)$ are all significantly positive in Model 2, which suggests that the failure hazards associated with the three inertia types are all significantly higher than purposive inertia. Results are consistent with the statistics exhibited in Table 1 . Therefore, H1 is supported. To visually contrast the differences in hazard ratios among the four types of inertia, this study employed the Kaplan-Meier plot to demonstrate the cumulative hazards for the four types of inertia across the entire observational period. As Fig. 1 clearly depicts, purposive inertia has the lowest failure hazard ratio across time, consistent with the statistical results.

To test $\mathrm{H} 2$, the observation time frame was set to the time period between 2003 and 2005 with an environment jolt caused by SARS. The results are reported in Model 4 of Table 3. Results show that the regression coefficients for coincidental inertia $(\beta=.171$, $p>.10)$ and habitual inertia $(\beta=-.043, p>.10)$ become insignificant. At the same time, the coefficient for restricted inertia also becomes marginally significant $(\beta=.735$, $p<.10)$. Taken together, these results suggest that the differences in the failure hazards associated with the four inertia types tend to converge when SARS imposes a severe environmental jolt, such that the failure hazards for all inertia types become more homogeneous compared with the findings in H1. The results are also consistent with the statistics reported in Table 1, that the gaps of failure rates between the SARS and non-SARS periods shrink for restricted, coincidental, and habitual inertia types. Therefore, H2 is supported.

H3 proposes the positive role of slack resources (specifically, absorbed slack), in strengthening the relative advantage of low failure hazard associated with purposive inertia. Tables 4 and 5 report the results for H3. The results in Table 4 show that while the four interaction terms between inertia types and unabsorbed slack are all negatively significant, it is the purposive inertia type that the absorbed slack resources can only contribute to mitigate its failure hazards over the time range $(2000-2011)(\beta=-11.261$, $p<.01)$ and during the SARS outbreak $(2003-2005)(\beta=-9.476, p<.01)$. These results coincide with the rationale of $\mathrm{H} 3$ that a long-term prospect of the accumulation or investment in absorbed slack resource fits with the central tenet of purposive inertia for organizational survival. Therefore, H3 is also supported. 


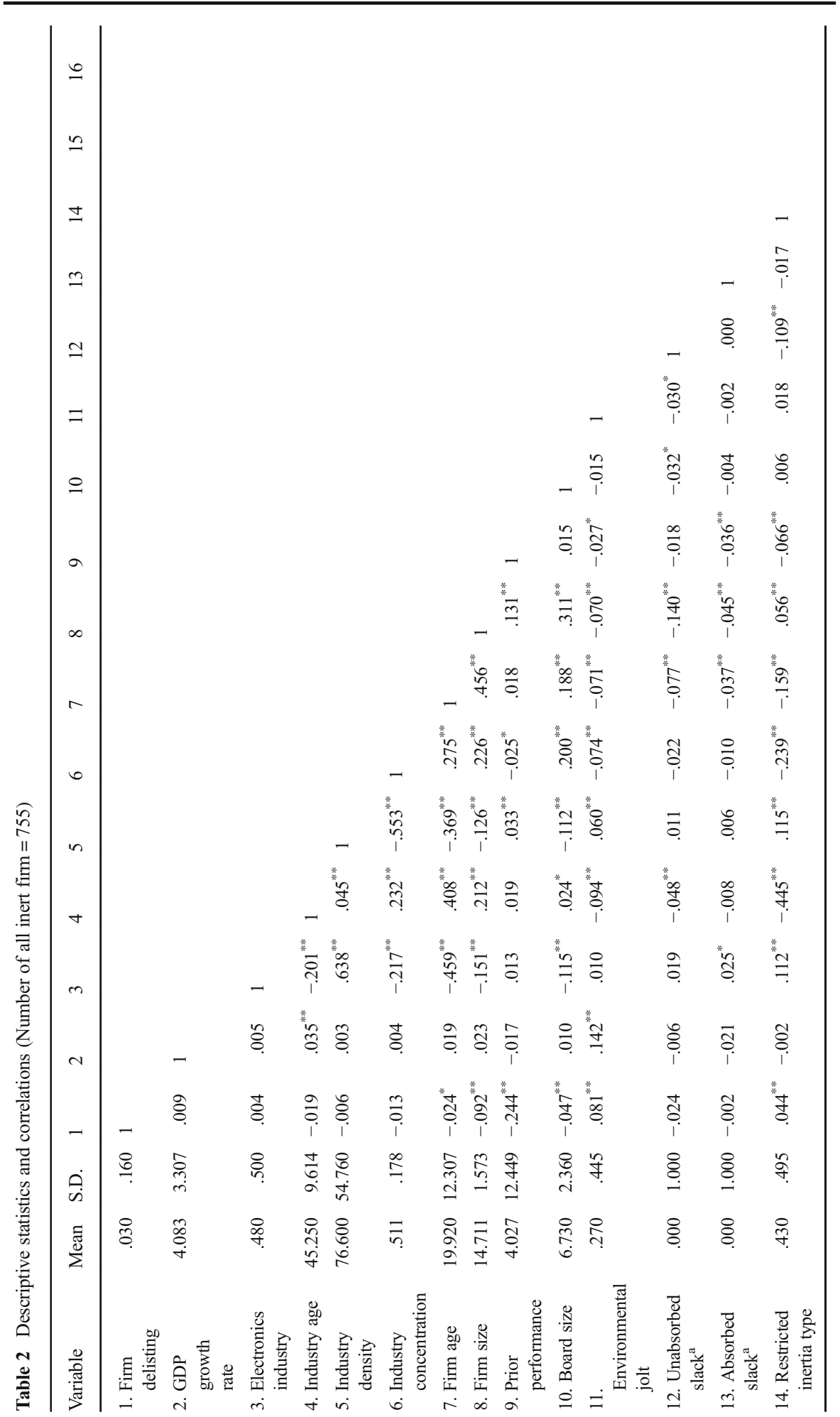




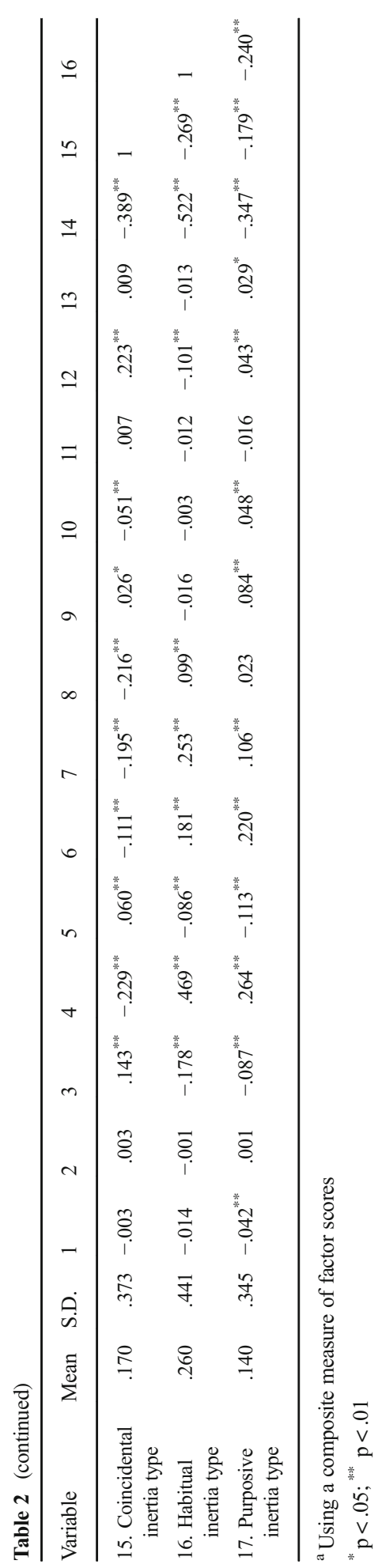


Table 3 Results of Cox proportional hazard regression for the effects of inertia types and environmental jolt

\begin{tabular}{|c|c|c|c|c|}
\hline & \multicolumn{4}{|l|}{ All inert firms } \\
\hline & Model 1 & Model 2 & Model 3 & Model 4 \\
\hline GDP growth rate & $-.012(.022)$ & $-.014(.022)$ & $.164(.152)$ & $.176(.152)$ \\
\hline Electronics industry & $-.230(.198)$ & $-.109(.202)$ & $-.038(.277)$ & $.146(.282)$ \\
\hline Industry age & $-.017^{\dagger}(.010)$ & $.004(.013)$ & $-.010(.014)$ & $.015(.019)$ \\
\hline Industry density & $.001(.002)$ & $.000(.002)$ & $-.001(.003)$ & $-.003(.003)$ \\
\hline Industry concentration & $-.003(.540)$ & $.087(.557)$ & $.498(.797)$ & $.563(.817)$ \\
\hline Firm age & $.002(.008)$ & $.002(.008)$ & $.010(.011)$ & $.011(.011)$ \\
\hline Firm size & $-.366^{* *}(.062)$ & $-.375^{* *}(.061)$ & $-.341^{* *}(.089)$ & $-.355^{* *}(.087)$ \\
\hline Prior performance & $-.020^{* *}(.002)$ & $-.021^{* * *}(.002)$ & $-.017^{* *}(.003)$ & $-.017^{* *}(.003)$ \\
\hline Board size & $-.084^{*}(.042)$ & $-.082^{\dagger}(.042)$ & $-.067(.056)$ & $-.070(.056)$ \\
\hline Environmental jolt ${ }^{\mathrm{a}}$ & $2.243^{* *}(.222)$ & $2.305^{* * *}(.223)$ & & \\
\hline Unabsorbed slack & $-1.174^{* *}(.314)$ & $-.753^{*}(.324)$ & $-.544(.344)$ & $-.277(.332)$ \\
\hline Absorbed slack & $-.554(.643)$ & $-.304(.549)$ & $-.066(.246)$ & $-.017(.180)$ \\
\hline Restricted inertia type ${ }^{b}$ & & $1.125^{* * *}(.342)$ & & $.735^{\dagger}(.415)$ \\
\hline Coincidental inertia type $^{b}$ & & $.681^{*}(.367)$ & & $.171(.464)$ \\
\hline Habitual inertia type ${ }^{b}$ & & $.618^{*}(.330)$ & & $-.043(.401)$ \\
\hline-2 Log-likelihood & $3,303.176$ & $3,288.384$ & $1,374.069$ & $1,366.290$ \\
\hline $\operatorname{LR} \chi^{2}$ & $700.609^{* *}$ & $713.492^{* *}$ & $132.103^{* *}$ & $138.319^{* *}$ \\
\hline Number of observations & 6,075 & 6,075 & 1,755 & 1,755 \\
\hline
\end{tabular}

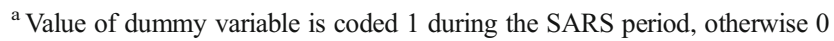

b Value of dummy variable is coded 1 , otherwise 0 , and purposive inertia type is set as the reference group Numbers in parentheses are standard errors $\dagger \mathrm{p}<.10 ; *<.05 ; * * \mathrm{p}<.01$

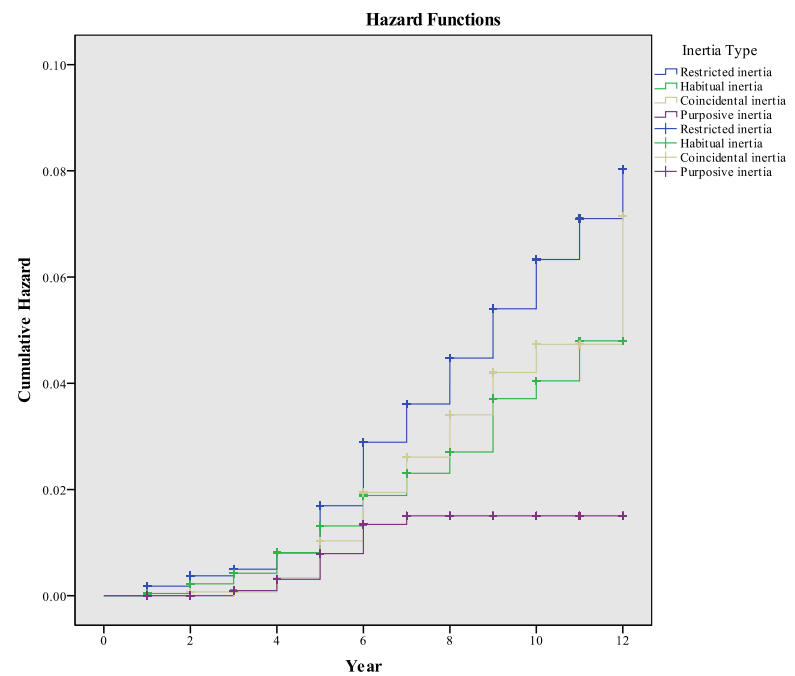

Fig. 1 Kaplan-Meier plot of hazard ratios for the four inertia types 


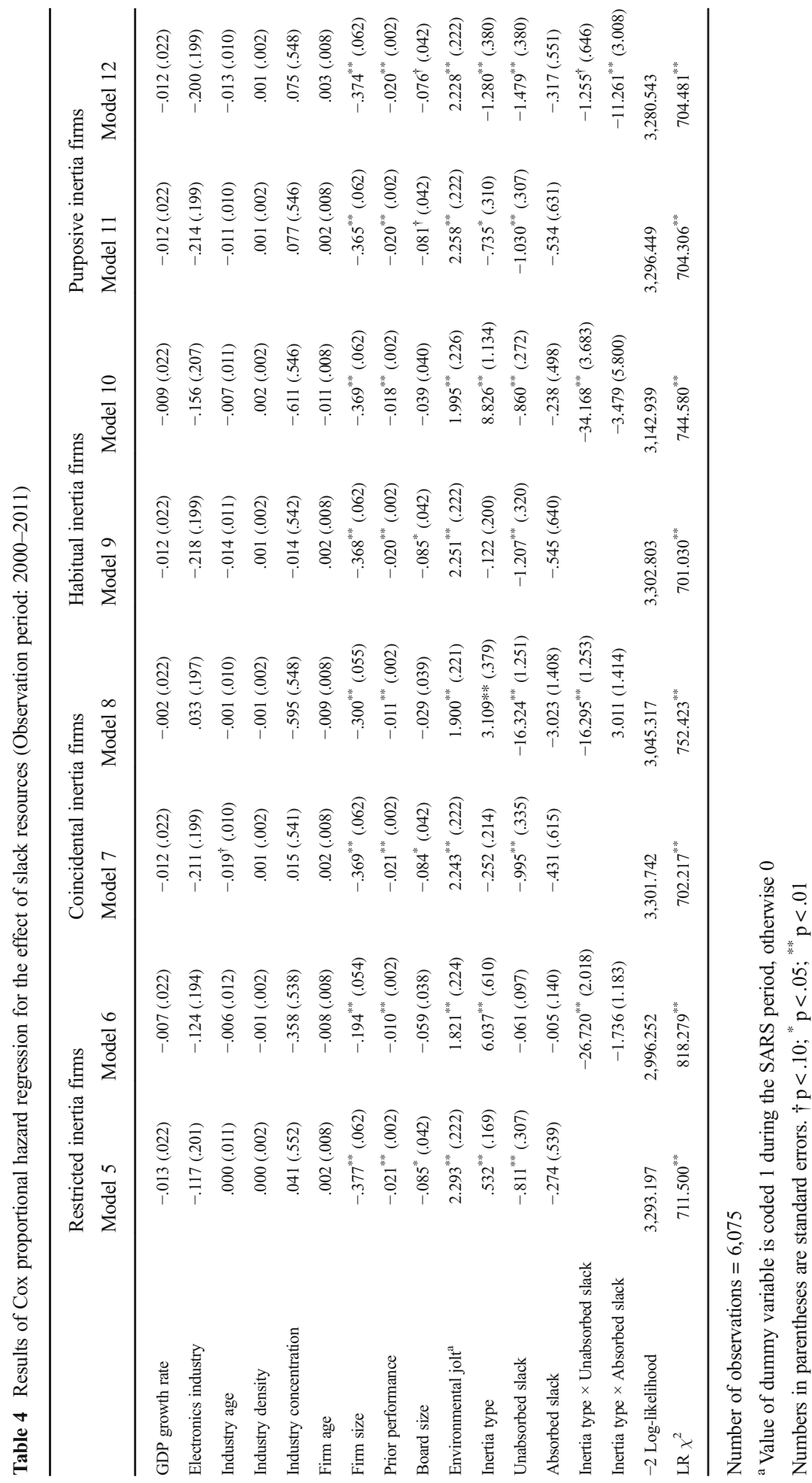




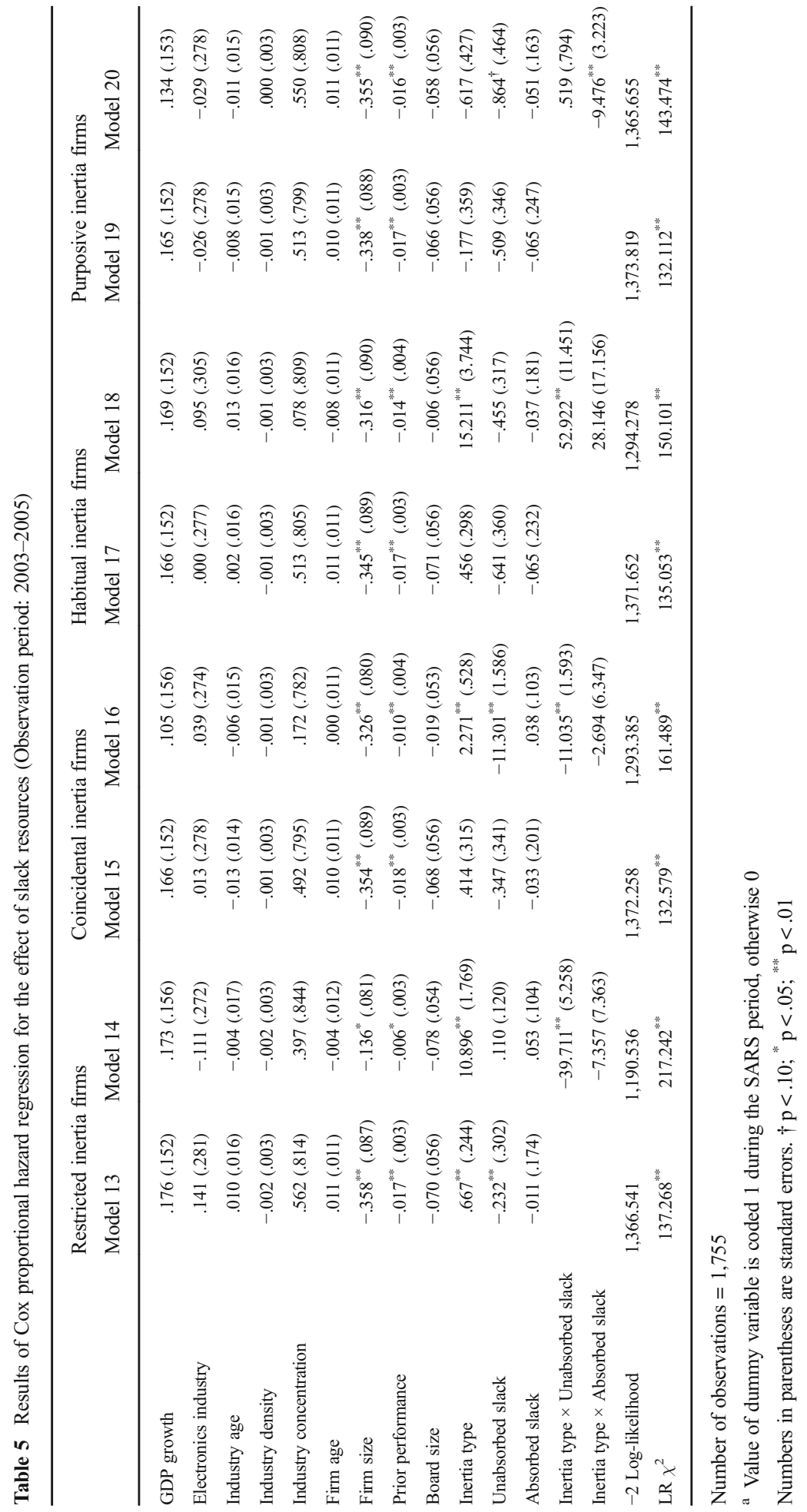


To test all the hypotheses for robustness check, we also utilized panel logit regression models. They indicate that as a set, results are highly consistent with those tested by Cox proportional hazard models.

\section{Discussion}

In this paper, we provide a more nuanced perspective on structural inertia in the context of failure hazards, recognizing that its recent theoretical development in organizational research has been progressively sidelined and has not advanced in parallel with empirical work. Findings show that different types of inertia lead to different failure hazard responses, moderated by environmental jolt and slack resources of the organizations. Consistent with Haveman and Kluttz's (2015) observation that ecologist researchers have built and refined each other's work thereby narrowing its appeal to this audience and limiting its ongoing extension, we present an alternative direction for development by proposing a classification of inertia by type. In appealing to both theorists and practitioners, part of the novelty of the classification approach is that we recognize inroads made since Hannan and Freeman $(1977,1984)$ incorporating the core features of structural inertia (timing, speed, and responsiveness) while adjusting the worldview that this organizational architecture is not necessarily fixed. The proposed mechanism highlights that there is more variety in and possible choices in an organization's structural options, noting the strength of inertial pressures on structure specifically arising from the selection associated with environment and from resources.

\section{Contributions}

In response to the problem with structural inertia having become seen as a sort of establishment theory and deeply embedded in dialog on organizations because of its historical placement, this paper makes four integrated contributions. As a set these contribution indicate the presence and use of different types of structural inertia in response to failure hazards, and especially demonstrating its applicable for emerging Asian economies.

As our primary contribution, and with our focus on engaging structural inertia, while acknowledging that there are already established variations in how inertia is represented, we contribute to discussion on organizational structure by showing that varying structural inertia by type enables a more dynamic understanding to studying and applying structure. With this classification, this addition is particularly relevant in the context of failure, and the tendency both by theorists and practitioners to view it as a disruption or an outcome to incorporate (Christensen \& Raynor, 2013). We note also that while empirically confirmed, inertia is historically represented as a distinct organizational structure that needs to be reproduced to keep organizations from changing. In response, we maintain that this inability to differentiate structural inertia limits its broader appeal because it overlooks its potential for evolution, an especially stark contrast given recent developments in theorizing on organizational ecology and in organizational change research. Through our findings, and broadening its foundation, we assert that different types of structural inertia enable different responses to failure hazards directed by environmental jolt pressure and resource slack, which can in turn 
enable organizational learning. This latter finding is especially helpful to practitioners attempting to manage the risk associated with failure hazards, given that it highlights the variability in this response. As Christensen (2013) showed for the rigid disk drive industry, the different responses to failure hazards taken by IBM and Seagate played a role in their respective experiences and risk-taking outcomes. Using the sentiment from Bruton et al.'s (2003) findings on turnaround, in this way our study suggests that the classification is applicable to a variety of industries and extended to different emerging markets.

Second, confirming the four types differences, this paper also contributes by indicating that there are alternative readings available of the association between inertia and performance outcomes. In this context, our goal was not to test the legitimacy of structural inertia, nor to theorize its underpinning idea. Rather, that there is a possible range of diversity in structural inertia that gives us the scope to understand better and tease apart the predicted patterning of failure responses. In this way, the classification by type offers a real extension to structural inertia debate, highlighting that it is far more dynamic and varied than previously characterized. This recognition offers a clear challenge to conventional thinking on organizational structure, encouraging theorists to reconsider established views on control and authority when dealing with failure. Confirming the nature of variations in the strength of inertia for organizations responding to failure also presents practitioners with a different path in how they think about organizational structure in this context. Thus, this study builds on recent advances centered on inertia (e.g., Håkonsson et al., 2013; Stieglitz et al., 2016; Yi et al., 2016) and opposes debate on whether it is too narrow or that it does not distinguish its features adequately (Donaldson, 1995; Gilbert, 2005).

Empirically, this paper thereby contributes to the understanding of firm structure, which can extend further into the important discussion on the option on and varieties of capitalism in Asia (Bruton, Peng, Ahlstrom, Stan, \& Xu, 2015; Carney, Gedajlovic, \& Yang, 2009). Our Taiwan sample embellishes this broadening as both an ideal corporate setting to test these relationships, and in advancing discussion of organizational structure in emerging economies, which remain an under-explored region for structural debate (e.g., Meyer \& Peng, 2016). It ratifies that even in dynamic and evolving market economies, structural inertia is far more dynamic than it is historically characterized and can differ by type in incorporating failure, moderated by environmental jolts and slack resources of the organization. These results promote a clear alternative to convention on how inertia thrives and is viewed, especially in the context of structures and change, and for those implementing change. This variability is especially pertinent to this market and assumptions about the limited role and placement of inertia, thought to be problematic in emerging East Asian environments (Liu, Wang, Zhao, \& Ahlstrom, 2013; Yang \& Schwarz, 2016).

In this regard, and specific to practitioners facing changing business conditions, we demonstrate that outside of environmental jolts, the failure hazards between each inertia type are heterogeneous. The practical contribution of this outcome suggests that those dealing with failure, closer attention should be paid to considering within-type variances in organizational architectures, instead of presenting the fundamental relationships among organizational structure, performance, and environment as necessarily isomorphic. This finding is informative given that our study shows that the differences found in failure hazard responses are associated with substantive differences in 
performance both between and within types (i.e., H1). In this respect, and growing the earlier example, IBMs turnaround from increased failure hazards in the 1990s (alongside large losses and high survival risk; Christensen, 2013) to decreased failure hazards in the 2000s (and integrated business solutions and turnaround; Harreld, O'Reilly, \& Tushman, 2007) associated with inertia's within-type variability. The emergence of this differentiation in a core feature of how organizations structure suggests that the assumed focus in ecology debate promoting structural inertia as a primary means of protecting the firm from uncertainty still has room for more focused future research. Doing so, this paper contributes to a better understanding of the linkages between structural inertia and associated risks of failure, which is a longstanding interest in organizational and strategy research.

Third, and with clear implications for organizations dealing with failure, with its focus on environmental jolts, we establish an alternative view of the nature of time in the emergence of structural inertia - that is, its temporal pattern. In structural inertia theory, organizational structure changes "initiate reorganization periods" (Hannan, Pólos, \& Carroll, 2007b: 293; Hannan \& Freeman, 1984), characterized by the time elapsed and the total time spent by individual units to reorganize. This timing increases the possibility for failure because of the risk it poses. In this context, it is assumed that the process of change is disruptive in the short run and adaptive in the long run, if the organization manages to overcome the initial disruption. By contrast, as we model it, the differences in the evolution and support of inertia types (i.e., H2) shows that failure hazards occurred within a relative short time span regardless of type. Evidence suggests that the relative advantages between each type diminish in the short-term (due to environmental jolts).

This observation on temporal patterning is significant given that historically, structural inertia research has focused on managing uncertainty by managing performance variability over time. In particular, the noticeable difference between purposive inertia and the three other types highlights both the different possible effects of long-term effects (i.e., H1) and the diminished capacity of shorter time frames (i.e., H2). As H3 emphasizes this study finds that investment in and accumulation of slack resources can offset time, meaning that adopting structural inertia in response to temporal pressure buffer the impact of unexpected environmental turbulence. This confirmation by type downplays the function of time in the selection process that is at the heart of inertia theory. Doing so, we contend that different structural inertia types can enjoy the advantages of directly responding to failure hazards rather than being regulated by time. While this finding needs more work, it has clear practical implications for managing failure - calling for attention to the response rather than a preoccupation with its timing. This sentiment is significant because inertia research typically supports ecology theory's main implication that change raises an organization's mortality risk, and its developments have tended to focus on empirically connecting change features to mortality (e.g., success bias, Barnett \& Pontikes, 2008 and cascades, Hannan et al., 2007a). While logical - after all, Hannan and Freeman's (1984) original thesis was titled "structural inertia and organizational change" - this focus on the structural approach to analyzing the shape and risk of change has allowed a degree of imprecision to creep into the terminology used to describe failure in the context of structural inertia. Our findings stress that inertia is a broader construct. Consequently, while requiring 
further testing, the classification is a means of expanding the scope of understanding differences in structural responses to failure.

Finally, in keeping with a core interest in this paper to develop debate on inertia, our findings are also a call to arms for broader progress in the level of analysis of structural inertia. By developing and then classifying categories of inertia we find that a firm can be a member of several different groups in responding to failure hazard, presenting inertia as a result of interactions between and within populations. Doing so, and leveraging advances made in strategy theory (e.g., behavioral foundations of strategic management, see Hodgkinson \& Healey, 2011) and institutional theory (e.g., microfoundations of institutionalism, see Powell \& Colyvas, 2008), we explicitly connect firm-level inertia to population-level failure hazards. This approach enables a broadening of debate on the possibility of multiple category types. While structural inertia debate is built on the need to incorporate the firm, the focus on the effects of inertia on organizational populations has obscured this interest, which is something our classification redresses. The benefit of adopting inertia types as a study lens is a significant advance in this way, given that inertia debate has consolidated its focus on common core features in how inertia emerges. Whereas typically structural inertia debate relates to how organizations seek out reliable performance because change increases the probability of failure, the classification provides a broader framework that considers the basis for and mechanism by which firms respond differently to failure hazards. By separating the dimensions for inertia by type based on population level environmental jolts and resource slack, and then linking the resultant firm level choices, the classification develops an alternative way to specify the persistence of structural inertia in the context of failure.

\section{Conclusion}

In providing support for differentiation in structural inertia responses our findings draw attention to a challenging theme for organizational researchers and practitioners. As indicated earlier, dealing with failure is a natural feature of organizations of all types. Yet research and commentary on organizational form in general and on structural inertia in particular has become somewhat marginalized by behavioral, institutional, and sensemaking-type accounts of organizing (see Hannan, 2005; Haveman \& Kluttz, 2015; Ruef, 2004). From this perspective, the problem with structural inertia is that while valued, extending it and adding to the diversity of its parts beyond additions to Hannan and Freeman's (1984) thesis have become progressively less widely adopted within the organizational research community. Given its history and empirical confirmation, structural inertia's relevance to organizations and to organizational debates is unquestioned. Yet the presence of organizational ecology has seen a large number of the positions adopted, pruned, or modified, focused on facilitating efficiency and flexibility in a way that limit its further development. After all, as Dew et al. (2006) showed, organizational ecologists often tend to view inertia as a cost incurred in order to attain what is perceived as more valuable benefits. In this sense, it is worth noting that inertia's original focus was to explain organizational diversity within populations, with many researchers relying on Hannan and Freeman's (1989: 65) own wording as a defense ("...we do not assume that organizations never change form"). It is in this 
context that our study expands debate in an emerging economy context by providing a more nuanced perspective on structural inertia, confirming that differences within structural inertia can lead to plottable differences in responses to failure hazards. Doing so helps to validate that structural inertia is a dynamic organizational form, relative to the choices and reasoning highlighted through the classification.

Such extensions are helpful for organizational practitioners too because they bring to the fore the recognition that with growing attention on organizational change and dynamic environments, the shift in organizations has been on how organizations manage tensions between stability and change (Ahlstrom, 2010). Yet, as we show, the core aspect of dealing with inertia - connecting change and failure - persists, and it is this feature that we develop in this paper in emphasizing structural inertia variations (while highlighting how inertia is still a fundamental aspect of organizing). Despite inertia being modeled in continuously changing environments and the consequent search for structural balance, when it comes to structural responses to failure, this paper has shown that traditional organizational ecology measures can be legitimately underplayed in favor of the characteristics of different structural inertia types. Structural inertia deserves ongoing exploration and attention with this classification in mind.

If there could be one primary message for this paper is would be that structural inertia is a far more dynamic and useful construct than it has been portrayed and it can be used more strategically by organizations experiencing failure (and those managing the experience). Our classification holds that when dealing with failure, there are a range of possible variations in inertia, suggesting that structurally inert organizations have flexibility in responding to conditions while still exhibiting features characteristic of this form of organizing. The adaptation of structural inertia by type in this way allows inertia to thrive over time in different markets. Therefore, the conditions that enable inertia differences (by type) show a range of inertia response choices available to senior management facing failure hazards, presenting different inertia pathways, which is important in dealing with failure and subsequent learning. Recognizing the features of this dynamism within structurally inert firms enables more pragmatic responses to failure, rather than the widely assumed necessity to adapt structure to manage associated pressures.

\section{References}

Agarwal, R., \& Sarkar, M. 2002. The conditioning effect of time on firm survival: An industry life cycle approach. Academy of Management Journal, 45(5): 971-994.

Ahlstrom, D. 2010. Innovation and growth: How business contributes to society. Academy of Management Perspectives, 24(3): 11-24.

Amburgey, T. L., Kelly, D., \& Barnett, W. P. 1993. Resetting the clock: The dynamics of organizational change and failure. Administrative Science Quarterly, 38(1): 51-73.

Bain, J. S. 1956. Barriers to new competition. Cambridge:Harvard University Press.

Barnett, W. P., \& Carroll, G. R. 1995. Modeling internal organizational-change. Annual Review of Sociology, 21: 217-236.

Barnett, W. P., \& Pontikes, E. G. 2008. The Red Queen, success bias, and organizational inertia. Management Science, 54(7): 1237-1251.

Barney, J. 1991. Firm resources and sustained competitive advantage. Journal of Management, 17(1): 99-120.

Baum, J. A., Dobrev, S. D., \& Van Witteloostuijn, A. 2006. Ecology and strategy. Oxford: Elsevier/JAI. 
Bennett, D., Chiang, C.-F., \& Malani, A. 2015. Learning during a crisis: The SARS epidemic in Taiwan. Journal of Development Economics, 112: 1-18.

Berger, J., \& Le Mens, G. 2009. How adoption speed affects the abandonment of cultural tastes. Proceedings of the National Academy of Sciences, 106(20): 8146-8150.

Birkinshaw, J., \& Haas, M. 2016. Increase our return on failure. Harvard Business Review, 94(5): 88-93.

Bourgeois, L. J. 1981. On the measurement of organizational slack. Academy of Management Review, 6(1): 29-39.

Bradley, S. W., Aldrich, H., Shepherd, D. A., \& Wiklund, J. 2011. Resources, environmental change, and survival: Asymmetric paths of young independent and subsidiary organizations. Strategic Management Journal, 32(5): 486-509.

Bromiley, P. 1991. Testing a causal model of corporate risk taking and performance. Academy of Management Journal, 34(1): 37-59.

Bruton, G. D., Ahlstrom, D., \& Wan, J. C. 2003. Turnaround in East Asian firms: Evidence from ethnic overseas Chinese communities. Strategic Management Journal, 24(6): 519-540.

Bruton, G. D., Peng, M. W., Ahlstrom, D., Stan, C., \& Xu, K. 2015. State-owned enterprises around the world as hybrid organizations. Academy of Management Perspectives, 29(1): 92-114.

Burke, W. W. 2017. Organization change: Theory and practice. Thousand Oaks:Sage.

Carney, M., Gedajlovic, E., \& Yang, X. 2009. Varieties of Asian capitalism: Toward an institutional theory of Asian enterprise. Asia Pacific Journal of Management, 26(3): 361-380.

Certo, S. T., Sirmon, D. G., \& Brymer, R. A. 2010. Competition and scholarly productivity in management: Investigating changes in scholarship from 1988 to 2008. Academy of Management Learning \& Education, 9(4): 591-606.

Cheng, J. L., \& Kesner, I. F. 1997. Organizational slack and response to environmental shifts: The impact of resource allocation patterns. Journal of Management, 23(1): 1-18.

Chou, J., Kuo, N.-F., \& Peng, S.-L. 2004. Potential impacts of the SARS outbreak on Taiwan's economy. Asian Economic Papers, 3(1): 84-99.

Christensen, C. M. 2013. The innovator's dilemma: When new technologies cause great firms to fail. Boston: Harvard Business Review Press.

Christensen, C. M., \& Raynor, M. E. 2013. The Innovator's solution: Creating and sustaining successful growth. Boston:Harvard Business Review Press.

Cox, D. R. 1972. Regression models and life-tables. Journal of the Royal Statistical Society. Series B (Methodological), 34(2): 187-220.

Daniel, F., Lohrke, F. T., Fornaciari, C. J., \& Turner, R. A. 2004. Slack resources and firm performance: A meta-analysis. Journal of Business Research, 57(6): 565-574.

Davis, J. P., Eisenhardt, K. M., \& Bingham, C. B. 2009. Optimal structure, market dynamism, and the strategy of simple rules. Administrative Science Quarterly, 54(3): 413-452.

de Figueiredo, R. J. P., Jr., Rawley, E., \& Rider, C. I. 2015. Why are firms rigid? A general framework and empirical tests. Organization Science, 26(5): 1502-1519.

Denrell, J., Liu, C., \& Mens, G. L. 2017. When more selection is worse. Strategy Science, 2(1): $39-63$.

Dew, N., Goldfarb, B., \& Sarasvathy, S. 2006. Optimal inertia: When organizations should fail. Ecology and Strategy, 23: 73-99.

Dobrev, S. D., \& Gotsopoulos, A. 2010. Legitimacy vacuum, structural imprinting, and the first mover disadvantage. Academy of Management Journal, 53(5): 1153-1174.

Dobrev, S. D., van Witteloostuijn, A., \& Baum, J. A. C. 2006. Introduction: Ecology versus strategy or strategy and ecology? Ecology and Strategy, 23: 1-26.

Dobrev, S. D., Kim, T.-Y., \& Carroll, G. R. 2003. Shifting gears, shifting niches: Organizational inertia and change in the evolution of the US automobile industry, 1885-1981. Organization Science, 14(3): 264 282.

Dolmans, S. A. M., van Burg, E., Reymen, I. M. M. J., \& Romme, A. G. L. 2014. Dynamics of resource slack and constraints: Resource positions in action. Organization Studies, 35(4): 511-549.

Donaldson, L. 1995. American anti-management theories of organization: A critique of paradigm proliferation. Cambridge: Cambridge University Press.

Dunbar, R. L. M., \& Ahlstrom, D. 1995. Seeking the institutional balance of power: Avoiding the power of a balanced view. Academy of Management Review, 20(1): 171-192.

Freeman, J., Carroll, G. R., \& Hannan, M. T. 1983. The liability of newness: Age dependence in organizational death rates. American Sociological Review: 692-710.

George, G. 2005. Slack resources and the performance of privately held firms. Academy of Management Journal, 48(4): 661-676. 
Gilbert, C. G. 2005. Unbundling the structure of inertia: Resource versus routine rigidity. Academy of Management Journal, 48(5): 741-763.

Goodstein, J., Gautam, K., \& Boeker, W. 1994. The effects of board size and diversity on strategic change. Strategic Management Journal, 15(3): 241-250.

Greenley, G. E., \& Oktemgil, M. 1998. A comparison of slack resources in high and low performing British companies. Journal of Management Studies, 35(3): 377-398.

Håkonsson, D. D., Klaas, P., \& Carroll, T. N. 2013. The structural properties of sustainable, continuous change: Achieving reliability through flexibility. Journal of Applied Behavioral Science, 49(2): 179-205.

Hambrick, D. C., \& D'Aveni, R. A. 1988. Large corporate failures as downward spirals. Administrative Science Quarterly, 33: 1-23.

Hamilton, G. G., \& Biggart, N. W. 1988. Market, culture, and authority: A comparative analysis of management and organization in the Far East. American Journal of Sociology, 94: S52-S94.

Hannan, M. T. 2005. Ecologies of organizations: Diversity and identity. Journal of Economic Perspectives, 19(1): 51-70.

Hannan, M. T., \& Freeman, J. 1977. Population ecology of organizations. American Journal of Sociology, 82(5): 929-964.

Hannan, M. T., \& Freeman, J. 1984. Structural inertia and organizational change. American Sociological Review, 49(2): 149-164.

Hannan, M. T., \& Freeman, J. 1989. Organizational ecology. Cambridge: Harvard University Press.

Hannan, M. T., Pólos, L., \& Carroll, G. R. 2003. Cascading organizational change. Organization Science, 14(5): 463-482.

Hannan, M. T., Pólos, L., \& Carroll, G. R. 2004. The evolution of inertia. Industrial and Corporate Change, 13(1): 213-242.

Hannan, M. T., Pólos, L., \& Carroll, G. R. 2007a. Cascading change. In M. T. Hannan, L. Pólos, \& G. R. Carroll (Eds.). Logics of organization theory: Audiences, codes, and ecologies: 231-255. Princeton: Princeton University Press.

Hannan, M. T., Pólos, L., \& Carroll, G. R. 2007b. Logics of organization theory: Audiences, codes, and ecologies. Princeton: Princeton University Press.

Harreld, J. B., O’Reilly, C. A., \& Tushman, M. L. 2007. Dynamic capabilities at IBM: Driving strategy into action. California Management Review, 49(4): 21-43.

Hassard, J., Cox, J. W., \& Rowlinson, M. 2013. Where are the old theories of organization? Prospects for retrospection in organization theory. Academy of Management Review, 38(2): 309-313.

Haveman, H. A. 1992. Between a rock and a hard place: Organizational change and performance under conditions of fundamental environmental transformation. Administrative Science Quarterly, 37: 48-75.

Haveman, H. A., \& Kluttz, D. N. 2015. Organizational populations and fields. In R. Scott, \& S. Kosslyn (Eds.). Emerging trends in the social and behavioral sciences: 1-15. New York: John Wiley \& Sons.

Heine, K., \& Rindfleisch, H. 2013. Organizational decline. Journal of Organizational Change Management, 26(1): 8-28.

Hodgkinson, G. P., \& Healey, M. P. 2011. Psychological foundations of dynamic capabilities: Reflexion and reflection in strategic management. Strategic Management Journal, 32(13): 1500-1516.

Kelly, D., \& Amburgey, T. L. 1991. Organizational inertia and momentum: A dynamic model of strategic change. Academy of Management Journal, 34(3): 591-612.

Lampel, J., \& Jha, P. P. 2017. Inertia, aspirations, and response to attainment discrepancy in design contests. $R \& D$ Management, 47(4): 557-569.

Lander, M. W., \& Heugens, P. P. M. A. R. 2017. Better together: Using meta-analysis to explore complementarities between ecological and institutional theories of organization. Organization Studies, 38(11): 1573-1601.

Le Mens, G., Hannan, M. T., \& Pólos, L. 2015a. Age-related structural inertia: A distance-based approach. Organization Science, 26(3): 756-773.

Le Mens, G., Hannan, M. T., \& Pólos, L. 2015b. Organizational obsolescence, drifting tastes, and age dependence in organizational life chances. Organization Science, 26(2): 550-570.

Lee, J.-W., \& McKibbin, W. J. 2004. Globalization and disease: The case of SARS. Asian Economic Papers, 3(1): 113-131.

Levinthal, D., \& Posen, H. E. 2007. Myopia of selection: Does organizational adaptation limit the efficacy of population selection?. Administrative Science Quarterly, 52(4): 586-620.

Lewis, S. 2015. The rise: Creativity, the gift of failure, and the search for mastery. New York: Simon and Schuster.

Liu, Y., Chen, Y. J., \& Wang, L. C. 2017. Family business, innovation and organizational slack in Taiwan. Asia Pacific Journal of Management, 34(1): 193-213. 
Liu, Y., Wang, L. C., Zhao, L., \& Ahlstrom, D. 2013. Board turnover in Taiwan's public firms: An empirical study. Asia Pacific Journal of Management, 30(4): 1059-1086.

McKendrick, D. G., \& Wade, J. B. 2010. Frequent incremental change, organizational size, and mortality in high-technology competition. Industrial and Corporate Change, 19(3): 613-639.

McKinley, W., Latham, S., \& Braun, M. 2014. Organizational decline and innovation: Turnarounds and downward spirals. Academy of Management Review, 39(1): 88-110.

McKinley, W., \& Mone, M. A. 2003. Micro and macro perspectives in organization theory: A tale of incommensurability. In H. Tsoukas, \& C. Knudsen (Eds.). The Oxford handbook of organization theory: 345-372. Oxford: Oxford University Press.

Mellahi, K., \& Wilkinson, A. 2010. Managing and coping with organizational failure: Introduction to the Special Issue. Group \& Organization Management, 35(5): 531-541.

Meyer, A. D. 1982. Adapting to environmental jolts. Administrative Science Quarterly, 27(4): 515-537.

Meyer, K. E., \& Peng, M. W. 2016. Theoretical foundations of emerging economy business research. Journal of International Business Studies, 47(1): 3-22.

Mishina, Y., Pollock, T. G., \& Porac, J. F. 2004. Are more resources always better for growth? Resource stickiness in market and product expansion. Strategic Management Journal, 25(12): 1179-1197.

Pearce, J. A., \& Zahra, S. A. 1992. Board composition from a strategic contingency perspective. Journal of Management Studies, 29(4): 411-438.

Peiris, J. S., Lai, S. T., Poon, L. L., Guan, Y., Yam, L. Y., Lim, W., Nicholls, J., Yee, W. K., Yan, W. W., Cheung, M. T., Cheng, V. C., Chan, K. H., Tsang, D. N., Yung, R. W., Ng, T. K., \& Yuen, K. Y. 2003. Coronavirus as a possible cause of severe acute respiratory syndrome. Lancet, 361(9366): 1319-1325.

Peli, G. L., Pólos, L., \& Hannan, M. T. 2000. Back to inertia: Theoretical implications of alternative styles of logical formalization. Sociological Theory, 18(2): 195-215.

Powell, W. W., \& Colyvas, J. A. 2008. Microfoundations of institutional theory. InR. Greenwood, C. Oliver, R. Suddaby, \& K. Sahlin (Eds.). The Sage handbookof irganizational institutionalism: 276-298. London: Sage.

Ruef, M. 2006. Boom and bust: The effect of entrepreneurial inertia on organizational populations. Ecology and Strategy, 23: 29-72.

Ruef, M. 2004. For whom the bell tolls: Ecological perspectives on industrial decline and resurgence. Industrial and Corporate Change, 13(1): 61-89.

Schwarz, G. M. 2012. The logic of deliberate structural inertia. Journal of Management, 38(2): 547-572.

Sharfman, M. P., Wolf, G., Chase, R. B., \& Tansik, D. A. 1988. Antecedents of organizational slack. Academy of Management Review, 13(4): 601-614.

Shepherd, D. A., Patzelt, H., \& Wolfe, M. 2011. Moving forward from project failure: Negative emotions, affective commitment, and learning from the experience. Academy of Management Journal, 54(6): 12291259.

Shimizu, K., \& Hitt, M. A. 2004. Strategic flexibility: Organizational preparedness to reverse ineffective strategic decisions. Academy of Management Executive, 18(4): 44-59.

Shumway, T. 2001. Forecasting bankruptcy more accurately: A simple hazard model. Journal of Business, 74(1): 101-124.

Simon, H. A. 1997. Administrative behavior: A study of decision-making processes in administrative organizations, 4th ed. New York: Free Press.

Simons, T., \& Ingram, P. 2004. An ecology of ideology: Theory and evidence from four populations. Industrial and Corporate Change, 13(1): 33-59.

Singh, J. V., \& Lumsden, C. J. 1990. Theory and research in organizational ecology. Annual Review of Sociology, 16: 161-195.

Skowronski, D. M., Astell, C., Brunham, R. C., Low, D. E., Petric, M., Roper, R. L., Talbot, P. J., Tam, T., \& Babiuk, L. 2005. Severe Acute Respiratory Syndrome (SARS): A year in review. Annual Review of Medicine, 56(1): 357-381.

Stieglitz, N., Knudsen, T., \& Becker, M. C. 2016. Adaptation and inertia in dynamic environments. Strategic Management Journal, 37(9): 1854-1864.

Suddaby, R., \& Foster, W. M. 2017. History and organizational change. Journal of Management, 43(1): 1938.

Sull, D. N. 2005. Why good companies go bad and how great managers remake them. Boston: Harvard Business Press.

Tan, J., \& Peng, M. W. 2003. Organizational slack and firm performance during economic transitions: Two studies from an emerging economy. Strategic Management Journal, 24(13): 1249-1263.

Thornhill, S., \& Amit, R. 2003. Learning about failure: Bankruptcy, firm age, and the resource-based view. Organization Science, 14(5): 497-509. 
Trahms, C. A., Ndofor, H. A., \& Sirmon, D. G. 2013. Organizational decline and turnaround: A review and agenda for future research. Journal of Management, 39(5): 1277-1307.

Ucbasaran, D., Shepherd, D. A., Lockett, A., \& Lyon, S. J. 2013. Life after business failure: The process and consequences of business failure for entrepreneurs. Journal of Management, 39(1): 163-202.

Voss, G. B., Sirdeshmukh, D., \& Voss, Z. G. 2008. The effects of slack resources and environmentalthreat on product exploration and exploitation. Academy of Management Journal, 51(1): 147-164.

Wan, W. P., \& Yiu, D. W. 2009. From crisis to opportunity: Environmental jolt, corporate acquisitions, and firm performance. Strategic Management Journal, 30(7): 791-801.

Wholey, D. R., \& Brittain, J. 1989. Characterizing environmental variation. Academy of Management Journal, 32(4): 867-882.

Wiersema, M. F., \& Bantel, K. A. 1992. Top management team demography and corporate strategic change. Academy of Management Journal, 35(1): 91-121.

Yang, K.-P., \& Schwarz, G. M. 2016. A multilevel analysis of the performance implications of excess control in business groups. Organization Science, 27(5): 1219-1236.

Yi, S., Knudsen, T., \& Becker, M. C. 2016. Inertia in routines: A hidden source of organizational variation. Organization Science, 27(3): 782-800.

Zaheer, S. 1995. Overcoming the liability of foreignness. Academy of Management Journal, 38(2): 341-363.

Gavin M. Schwarz ( $\mathrm{PhD}$, University of Queensland) is Associate Professor in the School of Management, at UNSW Business School, University of New South Wales. His research and work interests include organizational change and organizational inertia, with a particular focus in better understanding how organizations fail when changing, and developing applied strategies for dealing with failure to change. He is also interested in exploring how knowledge develops in organizational and change theory.

Kuo-Pin Yang ( $\mathrm{PhD}$, National Chengchi University) is Professor of Business Administration in the Department of International Business at National Dong Hwa University, Taiwan. His research interests include business strategy and innovation management, with particular emphasis on corporate governance and business groups in emerging economies.

Christine Chou (PhD, National Taipei University) is Associate Professor of International Business at National Dong Hwa University, Taiwan. Her current research interests mainly focus on technological innovation management, organizational learning, and open innovation.

Yu-Jen Chiu ( $\mathrm{PhD}$, National Dong Hwa University) is Assistant Professor of Marketing Management at the Oriental Institute of Technology. His research interests include consumer behavior, strategic management and entrepreneurship. 